\title{
Clinical Profile of Ocular Involvement in Head Injury
}

\author{
Sharma B ${ }^{1}$, Gupta $R^{2}$, Anand $R^{3}$ \\ ${ }^{1}$ Dr Bhavna Sharma, Assistant Professor, ${ }^{2}$ Dr Rachna Gupta, Associate Professor, ${ }^{3}$ Dr Reena Anand, Professor and Director, \\ All are affiliated with Regional Institute Of Ophthalmology, GMC, Bhopal, India
}

Address for Correspondence: Dr Rachna Gupta, Email: drrachnagupta2k@gmail.com

\begin{abstract}
Aim: This study was done to evaluate the simultaneous involvement of ocular structures in cases of head injury. Method: 96 cases of head injury were studied to note the associated ocular affections. It was a prospective nonrandomized analytical observational study. Patients of head Injury were evaluated for any ocular affection. Detailed history, Ophthalmological and neurological evaluation were done. All the relevant data was compiled and analyzed. Ocular manifestations were evaluated in each patient. Appropriate investigations were done to diagnose the cases of traumatic brain injuries. Results: It was observed that eyes are commonly affected in cases of head injury. Maximum numbers of patients were in the age group of 21-30 yrs (56\%). Males were commonly affected .Oedema \& echymosis of eyelids was the commonest affection (79\%), followed by conjunctival chemosis \& subconjunctival haemorrhage (75\%) and orbital wall fractures (54\%). Among the posterior segment affections, papilloedema and post neuritic optic atrophy were the common manifestations. Conclusion: It is important to evaluate all patients of head injury for any ocular involvement as well so that timely intervention can be done. A detailed ocular examination in such cases can save the life as well as the sight of the patients.
\end{abstract}

Keywords: papilloedema, haemorrhage, neurological.

\section{Introduction}

Topic of head injury is fairly important in present scenario of ever increasing commercialization and furthermore the rapidly increasing motorization of roads. Eyes being in proximity to skull bones also have equal risk to be involved in head injury. With exponentially increasing head injury cases, there has also been a simultaneous increase in ocular involvement in such cases. Keeping these facts under consideration the need to evaluate the clinical features of head injury with reference to ocular involvement, was felt. Head injury is a major public health problem and occurs most commonly in teenagers and young adults who would otherwise have been productive members of society ${ }^{1,2}$. Although head injuries have equally grave implications like many illnesses such as cancer, AIDS, heart disease, and diabetes, less research is targeting head injury than these diseases. Head injury is also commonly referred to as traumatic brain injury (TBI). The most common cause of TBIs is Motor vehicle accidents $^{3}$. The next most common cause is fall, and this mechanism is more common at the extremes of age i.e. paediatric and geriatric patients. Alcohol or other drug use contributes significantly to the occurrence of many head

Manuscript received: $23^{\text {rd }}$ july 2013

Reviewed: $26^{\text {th }}$ Sept 2013

Author Corrected: $19^{\text {th }}$ Oct 2013

Accepted for Publication: $14^{\text {th }}$ Nov 2013 injuries. Despite the protection extended to the eyes due to its placement in the orbit, the injuries to eyes are very common in association with head injury. This close association warrants the careful ocular examination in all cases of head injury. This study was done to evaluate the simultaneous involvement of ocular structures in cases of head injury.

\section{Methods}

This is a prospective analytical non randomized study of ocular manifestation of head injury based on clinical features of 96 patients. These patients were admitted in surgical wards, Orthopaedic or E.N.T. wards or presented as outdoor patients. All these patients were having the history or evidence of head injury. Patient's clinical notes were documented on a proforma noting their name age sex and addresses. The date and time of admission and duration of injury was noted, exact mode of injury and type of object that injured was also noted. All the symptoms of patients - Pain in eyes, blackout or diminution of vision, diplopia, bulging of eyeballs and bleeding from eyes after the injury was noted. History with special reference to the nature of the accident, the interval between injury and examination, history of convulsion after injury, state of consciousness from the

Available online at: www.ijmrr.in 250 | $P$ a g e


moment of injury till the time of examination, history of any drugs administered prior to admission and history of any significant concurrent or past illness (diabetes, hypertension, ischemic heart disease) was taken.

Detailed Ocular Examination was done including Vision recording, whenever possible. In the conscious, cooperative and mobile patients the visual acuity was recorded by using the hand held Snellen chart. In conscious but uncooperative and immobile patients the vision was recorded by Finger counting. Slit lamp aided ocular examination was done to examine any abnormality in Eye lid, Conjunctiva, Sclera, Cornea, Anterior chamber, Iris, Pupil, Lens. Defects in continuity of orbital rim were palpated for any crepitus $\&$ the position of outer canthus and inner canthus was seen for any displacement. Proptosis if any was noted. In conscious and co-operative patients, ocular movements were tested in nine direction of gaze. Fundus examination was done by direct Ophthalmoscope in every patient and with slit lamp biomicroscopy whenever required. All relevant Investigations were done - (a) X-ray skull Lateral and anteroposterior views of skull (b) X-ray OrbitAnteroposterior view and Lateral view (c) Diplopia Charting was done whenever found necessary. (d) CT scan wasdone in majority of patients.

\section{Results}

The present study of Ocular manifestation in 96 patients of head injury was conducted in a tertiary eye care Centre. In this series, the highest incidence 56\% was seen in the 21-30 years age group, followed by 20\% in 31-40 years age group. Majority of patients of head injury were in the age group of 11 to 40 years i.e. $83 \%$ with higher proportion of male (73\%) over females (27\%). Right eye was involved more then left eye (58\%)

Table No. 1: Showing Causative Factor of Head Injury

\begin{tabular}{|l|l|l|}
\hline S. No. & Causative Factor & Percentage \\
\hline $\mathbf{1 .}$ & RTA & 86 \\
\hline $\mathbf{2 .}$ & Fall from height & 10 \\
\hline $\mathbf{3 .}$ & Assault & 3 \\
\hline $\mathbf{4 .}$ & Unknown & 1 \\
\hline & Total & $\mathbf{1 0 0}$ \\
\hline
\end{tabular}

The commonest cause of Head Injury was RTA accounting for $86 \%$ of cases followed by fall and Assault-which accounted for $3 \%$ and $1 \%$ respectively.

Table No 2: Showing Type Of Fracture Of Orbit In Cases Of HeadInjury

\begin{tabular}{|l|l|}
\hline Orbit Wall & Percentage \\
\hline Medial Wall & 11 \\
\hline Lateral Wall & 29 \\
\hline Floor & 10 \\
\hline Roof & 4 \\
\hline Optic Canal & 0 \\
\hline
\end{tabular}

Fracture of orbit was seen in $54 \%$ of cases with $29 \%$ cases showing fracture of lateral wall followed by fracture of floor and medial wall in $(10 \%) \&(4 \%)$ cases respectively.

Table No 3: Showing Pupilliary Changes

\begin{tabular}{|l|l|l|}
\hline S. No. & Types of Pupil & Percentage \\
\hline 1. & Bilateral normal size reacting & 59 \\
\hline 2. & Bilateral semidilated not reacting to light & 11 \\
\hline 3. & Bilateral dilated fixed & 5 \\
\hline 4. & Bilateral constricted fixed & 3 \\
\hline 5. & Bilateral normal size sluggishly reacting & 3 \\
\hline 6. & Unilateral dilated fixed & 9 \\
\hline 7. & One dilated other constricted fixed pupil & 6 \\
\hline 8. & Unilateral dilated, direct reaction absent indirect present & 1 \\
\hline 9. & Bilateral constricted sluggishly reacting & 3 \\
\hline
\end{tabular}


Bilateral dilated not reacting to light pupil were seen in $11 \%$ of cases. Unilateral dilated not reacting to light pupil were seen in $9 \%$ of cases.

Table No. 4: Showing Involvement of Ocular Structures In Head Injury

\begin{tabular}{|c|c|c|}
\hline S. No. & Clinical Signs & Percentage \\
\hline \multicolumn{3}{|l|}{ Eyelid } \\
\hline 1. & Ecchymosis and Edema & 79 \\
\hline 2. & Tear & 8 \\
\hline 3. & Lag-Ophthalmos & 3 \\
\hline 4. & No involvement & 10 \\
\hline \multicolumn{3}{|c|}{ Conjunctiva } \\
\hline 1. & Chemosis & 22 \\
\hline 2. & Sub Conjunctival hemorrhage & 75 \\
\hline 3. & Tear & 3 \\
\hline \multicolumn{3}{|c|}{ Cornea } \\
\hline 1. & Tear & 1 case \\
\hline 2. & Exposure keratopathy & 3 case \\
\hline \multicolumn{3}{|c|}{ Anterior chamber } \\
\hline 1. & Hyphema & 1 case \\
\hline 2. & Hypopyon & 0 \\
\hline \multicolumn{3}{|l|}{ Iris } \\
\hline 1. & Prolapse & 1 case \\
\hline 2 & Tear & 0 \\
\hline
\end{tabular}

Edema / Ecchymosis of lids and subconjunctival hemorrhage were the most common ocular manifestation accounting $79 \%$ and $75 \%$ respectively. Involvement of cornea and anterior chamber was less common.

\section{Table No. 5: Fundus Changes In Cases of Head Injury}

\begin{tabular}{|l|l|l|}
\hline S. No. & Fundus changes & Percentage \\
\hline 1. & Normal disc & 58 \\
\hline 2. & Papilledema/disc oedema & 22 \\
\hline 3. & Disc pallor & 15 \\
\hline 4. & Pre retinal \& sup. Hemorrhage & 4 \\
\hline 5. & Vitreous hemorrhage & 1 \\
\hline
\end{tabular}

Maximum number of cases had normal fundus. Papilledema was seen in $22 \%$ of cases and disc pallor in $15 \%$ cases.

\section{Discussion}

The present study of ocular manifestation in head injury was carried out in 96 patients of Head trauma at RIO (Regional Institute of Ophthalmology) at Hamidia Hospital, Bhopal. Some of our observations are showing an increase in the incidence of ocular complication in particular. There is also a definite change in the pattern of Head injury and their ocular complications. This study included selected patient and was not a random study. Almost all patient were having moderate to serve head injuries. There is a definite increase in the number of on road vehicles in recent years and average speed of commuting vehicles has also increased. The fact, that unfortunately none of the patient in this series were putting on a helmet and hence having no protection from direct trauma to the head, also highlights the grim scenario with regards to self protection. In the present study, incidence of external injury to the head in frontal region was high which may be another factor for higher incidence of ocular manifestation in the present series. Young persons between the age group of 21-30 yearswere particularly prone to head injury accounting for $56 \%$ of cases in this series. The next common age group was 31 40 years $(20 \%)$, this can be explained on the basis of active life of young people $.20 \%$ caseswere in the age 
group of 11-20 years. $90 \%$ cases reported in this series were males due to occupational commutation. Other studies $[1,2]$ also showed almost similar observations .The proportion of head injuries- $86 \%$ resulting from RTA is higher than ,44\% quoted by Rowbotham, et al 4 .NSD Raju [2] reported $47.5 \%$ cases because of RTA and $32.5 \%$ cases due to fall from height.We can see marked increase in RTA as the cause of head injury as compared to past studies. This can be attributed to increase in motorization of roads and ironically the decrease in awareness about use of safety measures like Helmets.

The next common cause of head injury was fall from height followed by assault. In the present series $60 \%$ of cases had history of unconsciousness. King and Walsh [5] stated that there may be a short period of unconsciousness following Head injury. Fracture of orbit was seen in 54\% of cases.Lateral wall fracture was of commonest occurrence (29\%).kulkarny etallobserved $12 \%$ cases of orbital fractures in their series. According to Duke Elder [6] ,injury to orbit and to surrounding skull is a common cause of orbital fracture .In the present series Edema\&Ecchymosis of lids and subconjunctival hemorrhage were the most common ocular manifestation accounting for $79 \%$ and $75 \%$ respectively. Our observationsshow higher incidence as compared to other studies $[1,2,7,8,9]$.

However certain other studies10 reported very high incidence of conjunctival and lid involvement i.e. 92.5\%. The cornealinvolvement was seen in 4 cases, out of which exposure keratopathy was seen in [3] cases and corneal tear in [1] case.Kulkarnyetal [1] observed corneal epithelial defect in $16.7 \%$ and corneal /sclera tear in $2 \%$ cases. In our study the incidence of corneal involvement in head injury was low as compared to other studies $[8,11]$. The lower incidence of corneal involvement in present series may be due to less number of open globe injury in cases of head injury. Anterior chamber involvement was seen in1case, in the form of hyphema which is nearly equal to Macewen JC et al [11] who reported $0.5 \%$ cases ofhyphema. Irisprolapse occurred in [1] case. The incidence is very low than that of Parmer IPS et al [12], who reported a very high incidence of $32.64 \%$.kulkarnyetall observed hyphemain combination of other ocular findings such as ecchymosis, subconjunctivalhemorrhage, orbital fracture, hyphaema, and scleral tears

Pupillary involvement was seen in $41 \%$ cases which are less than that reported byBlakeslee [13]. Kulkarnyetal1\&Masilaetal [8] reported $16.5 \%$ and $21.75 \%$ cases of papillary involvement respectively. Unequal sizedpupils were seen in $16 \%$, showing anisocoria .Bilateral dilated pupils were seen in 5\%cases. Blackslee [13] reported 5.5\%chances of survival in cases of bilateral dilated pupils. This indicates the development of raised supratentorialpressure due to hemorrhage or cerebral oedema, leading to gross cerebral shift causing the temporal lobe to herniate into tentorial hiatus so as to stretch IIIrd nerve [6]. The appearanceof optic disc was normal in $58 \%$ of cases.Papilloedema was observed in $22 \%$ of cases in present series.

It is consistent with findings of MasilaEtal [8] Papilloedema is generally due to secondary manifestations of cerebral injury producing raised intracranial tension. This is well co-related withYadama SM ,etal [14] who reported that papilloedema may occur due to mildly raised ICP and trapped subarachnoid CSF around the optic nerve.kulkarny et al [1] reported 5.8\% incidence of papilloedema. Pre retinal Hemorrhage and Vitreous hemorrhage was seen in $4 \%$ and $1 \%$ cases respectively.It was almost similar as in other studies. $[15,16]$

\section{Conclusion}

The immense increase in the problem ofhead injury in present era has necessitated this study aimed at analyzing the cause, pattern, \& identifications of clinical features. This may further aid in thesubsequent management of any ocular affections. The various conclusion derived in our study are as follows: Majority of patient of head injury were in the age group of 11 to 40 years with increase proportion of male over females. Right eye is involved more then left eye. Ecchymosis\& edema of eye lids \&Subconjunctivalhemorrhage was seen inhigher proportions.

Lateral wall fracture wasthe commonest type, of orbital fractures seen. In cases of head injury frontal bone fracture was commonest, which was associated with orbital fractures. Pupillary changes were found in $41 \%$ of cases. Fundus changes showed papilledema / disc hyperemia in $20 \%$ cases and disc pallor in $15 \%$ Cases. Thus it can be concluded that head injury can result in varied ocular involvement as well.

Saving the life of the patient may seem to be the immediate goal, but saving the sight should also be an important target of treatingsurgeon. Ocular involvement in cases of head injury should also be carefully evaluated, which can go a long way in saving the life and sight of the patient.

Funding: Nil, Conflict of interest: Nil

Permission from IRB: Yes 


\section{References}

1. Kulkarni AR, Aggarwal SP, Kulkarni RR, Deshpande MD, Walimbe PB, Labhsetwar AS. Ocular manifestations of head injury: a clinical study;Eye (Lond). 2005 Dec;19(12):1257-63.[PubMed]

2. Raju N. Ocular manifestations in head injuries. Indian J Ophthalmology 1983;31:789-92. [PubMed]

3. Gururaaj G.Epidemiology of traumatic brain injuries: Indian scenario.Neurol Res. 2002 Jan;24(1):24. [PubMed]

4. G. F. Rowbotham, I. N. Maciver, DicksonJune, and Marjorie E. Bousfield; Analysis of 1,400 Cases of Acute Injury tothe Head ; Br Med J. 1954 March 27; 1(4864): 726-730. [PubMed]

5. King A B, Walsh FB trauma to head with particular reference to ocular science American journal of ophthalmology $1949 ; 32-191$.

6. Duke Elder Text book of ophthalmologyvol-14 part 1 (Henry Kimpton London) 1972.

7. Malik SRK, Gupta AK, Chaudhry S ; 280 cases of non-occupational injuries in delhi; Indian journal of ophthalmology;1968; 16- 178. [PubMed]

8. Masila, Faith Vata; Nairobi Ocular findings in patients with head injury at Kenyatta National Hospital2012 college of health sciences CHS 1523.
9. Claude L. Cowan Associated Eye Signs and Symptoms of Head Injuries J Natl Med Assoc;1983 : 31 : 6 : 789792.

10. Shukla B, Khanna B. Trauma index-a system of evaluation of ocular damage due to trauma. Indian $\mathrm{J}$ Ophthalmology 1983;31:439-41. [PubMed]

11. Macewan JC Eye Injuries. A prospective study of 5671 cases Br Journal of ophthalmology 1989 ;88890. [PubMed]

12. ParmarIPS,NaagpalRC, Sunandan S Pattern of ocular injuries in Haryana. Indian journal of Ophthalmology; 1985 ;33; 141-4. [PubMed]

13. Blakeslee GA, Arch ophthalmology (chicgo)2;566572.,1929.

14 .Yamada SM, Teramoto A, Yamada S, Hoshiai YC; . Severe papilledema identified 3 weeks after head injury.; Neurol Med Chir (Tokyo). 2002 Jul;42(7):293-6. [PubMed]

15 .Nippon GankaGakkaizasshi;MYamamoto; EUchio; T Kohno; Hajime Inomata - Statistical study of Ocularinjuries--effect of the seat belt legislation in traffic.Brain research bulletin 1988;20(5):573-9. [PubMed]

16 .T O Odebode1, DS Ademola-Popoola, TA Ojo and AA Ayanniyi ;Ocular and visual complications of Headinjury; Eye 2005 - 19, 561-566. [PubMed]

\section{How to cite this article?}

Sharma B, Gupta R, Anand R. Clinical Profile of Ocular Involvement in Head Injury. Int J Med Res Rev 2013;1(5):250-254. doi:10.17511/ijmrr.2013.i05.07. 